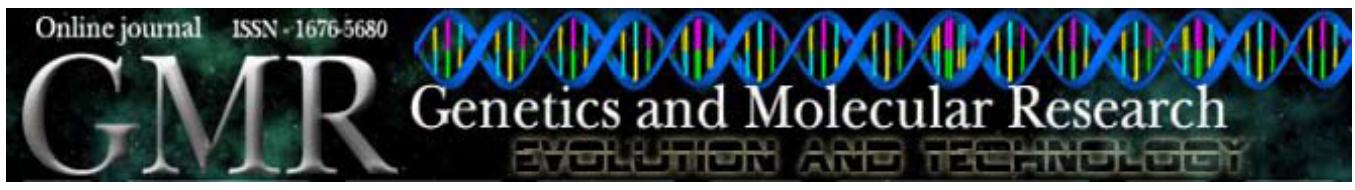

\title{
Africanized honey bees are efficient at detecting, uncapping and removing dead brood
}

\author{
M.M. Morais ${ }^{1}$, T.M. Francoy ${ }^{2}$, R.A. Pereira ${ }^{1}$, D. De Jong ${ }^{2}$ and \\ L.S. Gonçalves ${ }^{1}$ \\ ${ }^{1}$ Departamento de Biologia, Faculdade de Filosofia, \\ Ciências e Letras de Ribeirão Preto, \\ Universidade de São Paulo, Ribeirão Preto, SP, Brasil \\ ${ }^{2}$ Departamento de Genética, Faculdade de Medicina de Ribeirão Preto, \\ Universidade de São Paulo, Ribeirão Preto, SP, Brasil \\ Corresponding author: M.M. Morais \\ E-mail:mmanfrini@rge.fmrp.usp.br
}

Genet. Mol. Res. 8 (2): 718-724 (2009)

Received December 12, 2008

Accepted January 26, 2009

Published June 23, 2009

\begin{abstract}
The hygienic behavior of honey bees is based on a two-step process, including uncapping and removing diseased, dead, damaged, or parasitized brood inside the cell. We evaluated during periods of $1 \mathrm{~h}$ the time that hygienic and non-hygienic colonies of Africanized honey bees spend to detect, uncap and remove pin-killed brood using comb inserts with transparent walls placed in observation hives. We observed that hygienic colonies are significantly faster in detecting, uncapping and removing dead brood in the cells $(\mathrm{P}<0.001)$.
\end{abstract}

Key words: Apis mellifera; Hygienic behavior; Africanized honey bee; Observation hives 


\section{INTRODUCTION}

The hygienic behavior of Apis mellifera consists of the detection by workers of diseased, dead or damaged brood. This detection is normally followed by the uncapping of the cells and selective removal of the abnormal brood. Hygienic behavior is genetically controlled by two pairs of recessive genes $(\mathrm{u}=$ uncapping and $\mathrm{r}=$ removal). When in homozygosis $(\mathrm{uu} / \mathrm{rr})$, they allow the bee to detect and to remove the abnormal brood (Rothenbuhler, 1964a,b). Though other researchers have suggested different numbers of genes responsible for the control of this behavior (Moritz, 1988; Gramacho, 1999; Lapidge et al., 2002), the hypothesis of Rothenbuhler is the only one that has been experimentally proved.

Considerable intra-colonial variability is found in A. mellifera colonies, due to the large number of males that mates with each queen (Adams et al., 1977), leading to the production of several subfamilies inside a colony (Page and Robinson, 1991). All colonies are able to detect and remove diseased or dead brood, but at different rates (Gramacho and Spivak, 2003). The expression of this behavior can vary at the colony or the individual level (Spivak et al., 2003). Typically, bees from a hygienic colony uncap and remove abnormal brood faster than those from a non-hygienic colony.

Though it is a very relevant behavior for disease tolerance, the mechanisms used by bees to identify dead or diseased brood are not well understood.

Masterman et al. (2001) demonstrated through proboscis extension reflex experiments that hygienic bees can discriminate between healthy and diseased brood at lower thresholds than nonhygienic bees. Gramacho and Spivak (2003) also found that bees that are uncapping cells are more sensitive to odors than those that are removing the brood.

Gramacho (1999) was the first to study the uncapping and removal time of dead brood in colonies of A. m. carnica. Palácio et al. (2005) evaluated the time that selected hygienic and nonhygienic colonies of European bees spend to uncap and remove dead brood in observation hives; they concluded that hygienic colonies are much more efficient than are non-hygienic colonies.

It is well known that Africanized bees are resistant to brood diseases and that one of the factors that lead to this resistance is their accentuated hygienic behavior. We examined the time for uncapping and removal of dead brood by hygienic and non-hygienic colonies of Africanized honey bees.

\section{MATERIAL AND METHODS}

Seventy colonies of Africanized honey bees were tested for hygienic behavior using the pin-killing test (Newton and Ostasiewsk, 1986, modified by Gramacho and Gonçalves, 1994). These colonies were classified into three different groups according to the percentage of removed brood after $24 \mathrm{~h}$. Those that removed a mean of $80 \%$ or more of the dead brood were classified as hygienic $(\mathrm{H})$ colonies and those that removed a mean of $40 \%$ or less were classified as non-hygienic ( $\mathrm{NH})$. The colonies that removed between 41 and $79 \%$ were classified as intermediate and were not used in this study. These percentages were obtained from three consecutive tests, with an interval of 15-20 days between them.

The four $\mathrm{H}$ and four $\mathrm{NH}$ colonies with the most extreme values were selected and queens were produced from two colonies of each type. They were instrumentally inseminated with the semen of about 10 drones, which were produced by the other two colonies and introduced into four-frame-Langstroth nuclei. After 60 days, two $\mathrm{H}$ and two NH ob- 
servation hives were mounted using bees from these colonies in order to measure the time for uncapping and removal of the dead brood.

For better visualization of hygienic behavior, the observation hives were adapted with the introduction of a small "spinning frame". This consists of a small piece of comb inserted between two glass plates that measure $2.5 \mathrm{~cm} \times 15 \mathrm{~cm} \times 5 \mathrm{~mm}$, with a small wood block at each extreme (Figure 1). These spinning frames were introduced into normal Langstroth hives in our apiary in Ribeirão Preto ( $21^{\circ} 10^{\prime} 06^{\prime \prime}$ 'S 46 $\left.51^{\prime} 36^{\prime \prime} \mathrm{W}\right)$. When the brood was between 10 and 14 days old, the spinning frame was removed from the colonies, the brood was pin-killed using a number 1 entomological pin and the spinning frame was introduced into the observation hive. The spinning frame allows observation of the whole process of uncapping and removal, facilitating the visualization of the contact between adult bees and the dead brood during the hygienic process.

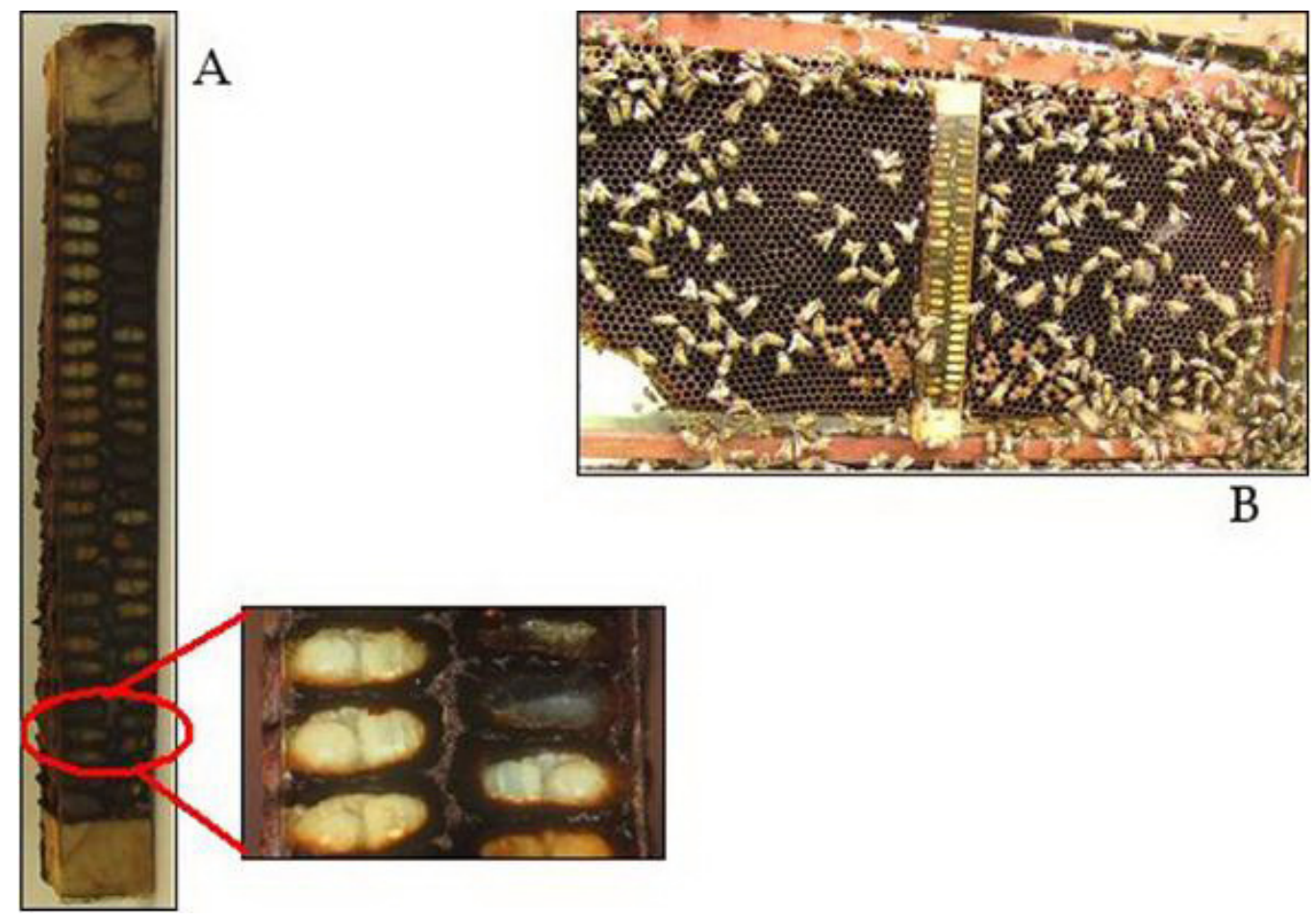

Figure 1. A. Small spinning frame with pupae between 10 and 14 days old. B. Small spinning frame inserted in a normal frame inside an observation hive.

Ten pupae were killed for each of the three tests and the uncapping and removal stages were recorded using the methodology proposed by Palácio et al. (2005). We inspected the removal stages at intervals of $1 \mathrm{~h}$, from $0 \mathrm{~h}$ until the complete removal of the dead brood.

The following codes were used to identify the uncapping stages: U0 - Only the hole made by the pin-killing test was detected. No honey bee activity was detected. U1 - Less than half of the capping were removed. U2 - Fifty percent of the capping were removed. U3 - More than half of the capping were removed. U4 - The cell was completely uncapped. 
The stages of removal were identified as follows: R0 - The worker brood was untouched. R1 - The honey bees began removal but the worker brood was still inside the cell. R2 - Less than 50\% of the worker brood were removed. R3 - Fifty percent of the worker brood were removed. R4 - More than 50\% of the worker brood were removed. R5 - Less than $50 \%$ of the worker brood remained in the bottom of the cell. R6 - Worker brood was totally removed.

Sixty cells were analyzed for each group (hygienic and non-hygienic) and the mean times of detection, uncapping and removal were compared using the Mann-Whitney test.

\section{RESULTS}

We compared the stages of uncapping and removal of $\mathrm{H}$ and $\mathrm{NH}$ bees. The $\mathrm{H}$ bees were significantly faster at detecting dead brood in the cells than the NH bees $(\mathrm{P}<0.001)$ (Table 1). We considered the time of detection the moment when the brood was first uncapped in any stage. Within $1 \mathrm{~h}$ after the beginning of the test, $43 \%$ of the dead brood had already been detected in $\mathrm{H}$ against $25 \%$ in $\mathrm{NH}$. After $3 \mathrm{~h}, 93 \%$ of the dead brood had already been detected in $\mathrm{H}$ against $70 \%$ in $\mathrm{NH}$. The maximum time that a brood remained undetected was $6 \mathrm{~h}$ in $\mathrm{H}$ against $28 \mathrm{~h}$ in NH (Figure 2).

Table 1. Total time spent by hygienic and non-hygienic Africanized bees for detecting, uncapping and removing the dead brood in hours since the perforation of the brood.

\begin{tabular}{lcr}
\hline & Hygienic & Non-hygienic \\
\hline Total detection time & $0.90 \pm 1.13^{\mathrm{a}}$ & $2.93 \pm 4.87^{\mathrm{b}}$ \\
Total uncapping time & $2.20 \pm 1.50^{\mathrm{a}}$ & $5.65 \pm 5.34^{\mathrm{b}}$ \\
Total removal time & $5.95 \pm 3.16^{\mathrm{a}}$ & $12.40 \pm 5.79^{\mathrm{b}}$ \\
\hline
\end{tabular}

Different letters in the same row indicate significant differences $(\mathrm{P}<0.001)$.

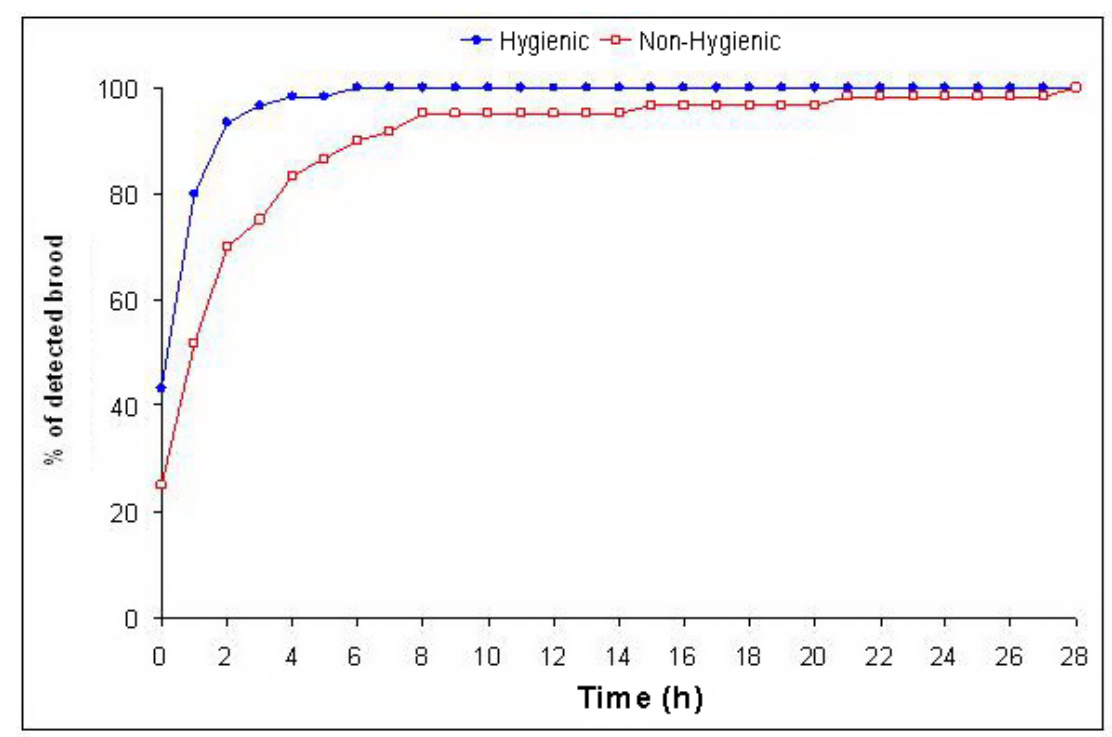

Figure 2. Time of detection of the pin-killed brood by hygienic and non-hygienic bees in observation hives. 
The total time of uncapping was significantly different in $\mathrm{H}$ and $\mathrm{NH}(\mathrm{P}<0.001)$ with $\mathrm{H}$ being more efficient (Table 1 ). After $1 \mathrm{~h}, 43 \%$ of the dead brood were completely uncapped in $\mathrm{H}$ and just 7\% in NH. The most pronounced difference between two observation times was $2 \mathrm{~h}$ after perforation, when $67 \%$ of the brood in $\mathrm{H}$ colonies were already uncapped against $25 \%$ in NH colonies. The maximum time to uncap a cell was $7 \mathrm{~h}$ in $\mathrm{H}$ and $29 \mathrm{~h}$ in $\mathrm{NH}$ (Figure 3).

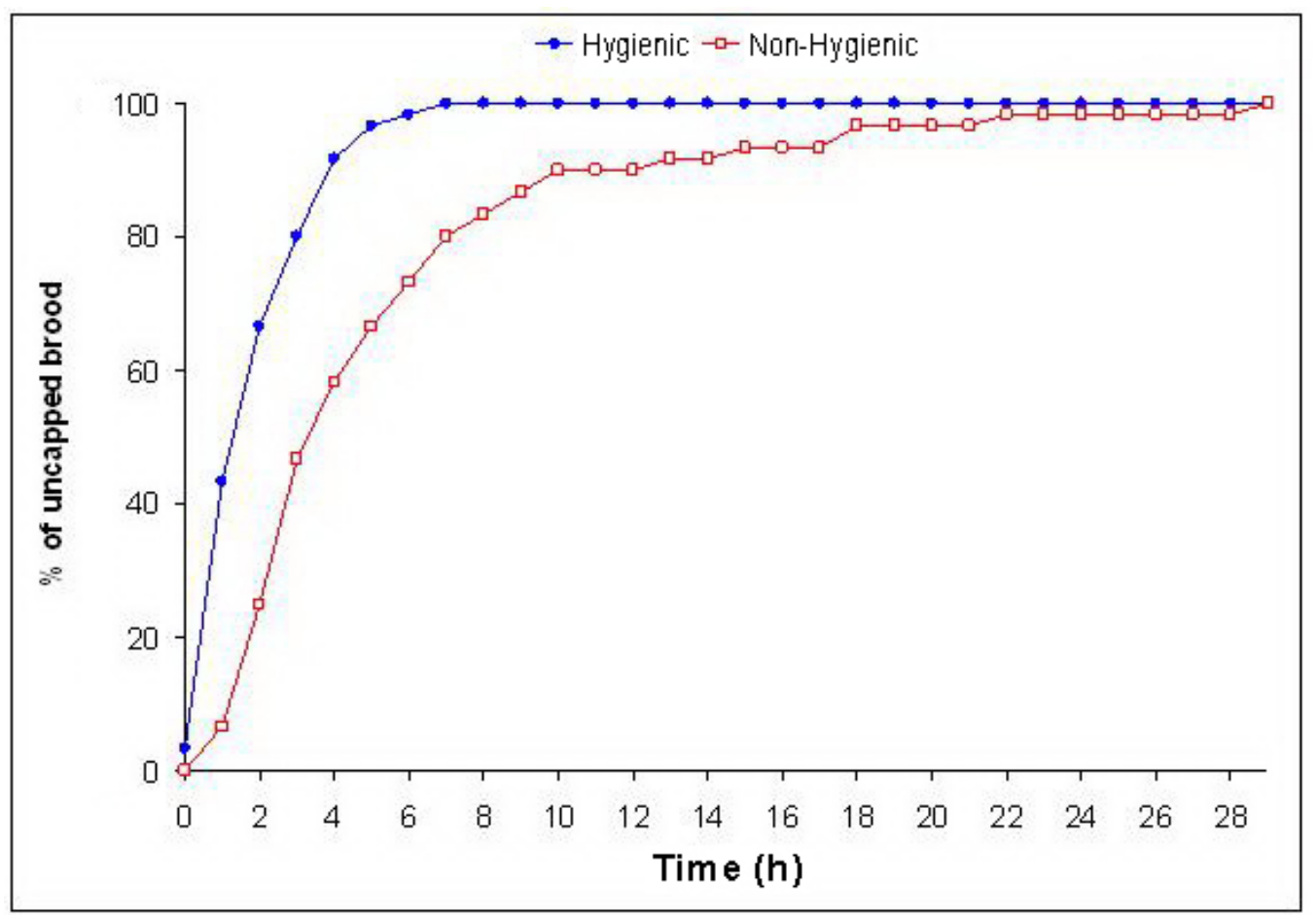

Figure 3. Total time of uncapping of dead brood by hygienic and non-hygienic Africanized bees after the perforation of the cell.

The total time until removal of the dead brood was also significantly shorter in $\mathrm{H}$ colonies than in $\mathrm{NH}$ colonies $(\mathrm{P}<0.001$; Table 1$)$. NH colonies took $6 \mathrm{~h}$ to completely clean out the first brood cell. At this time, $53 \%$ of the dead brood had already been removed by $\mathrm{H}$ colonies. The most pronounced difference between the two groups in this task occurred $8 \mathrm{~h}$ after perforation, when $87 \%$ of the brood had already been removed in $\mathrm{H}$ colonies and just $32 \%$ in the NH colonies (Figure 4). The maximum time to remove a dead pupa by the $\mathrm{H}$ colonies was $15 \mathrm{~h}$, while the $\mathrm{NH}$ colonies took $35 \mathrm{~h}$. The $\mathrm{H}$ colonies removed two dead pupae less than 10 min after perforation, demonstrating the great sensibility of these bees. 


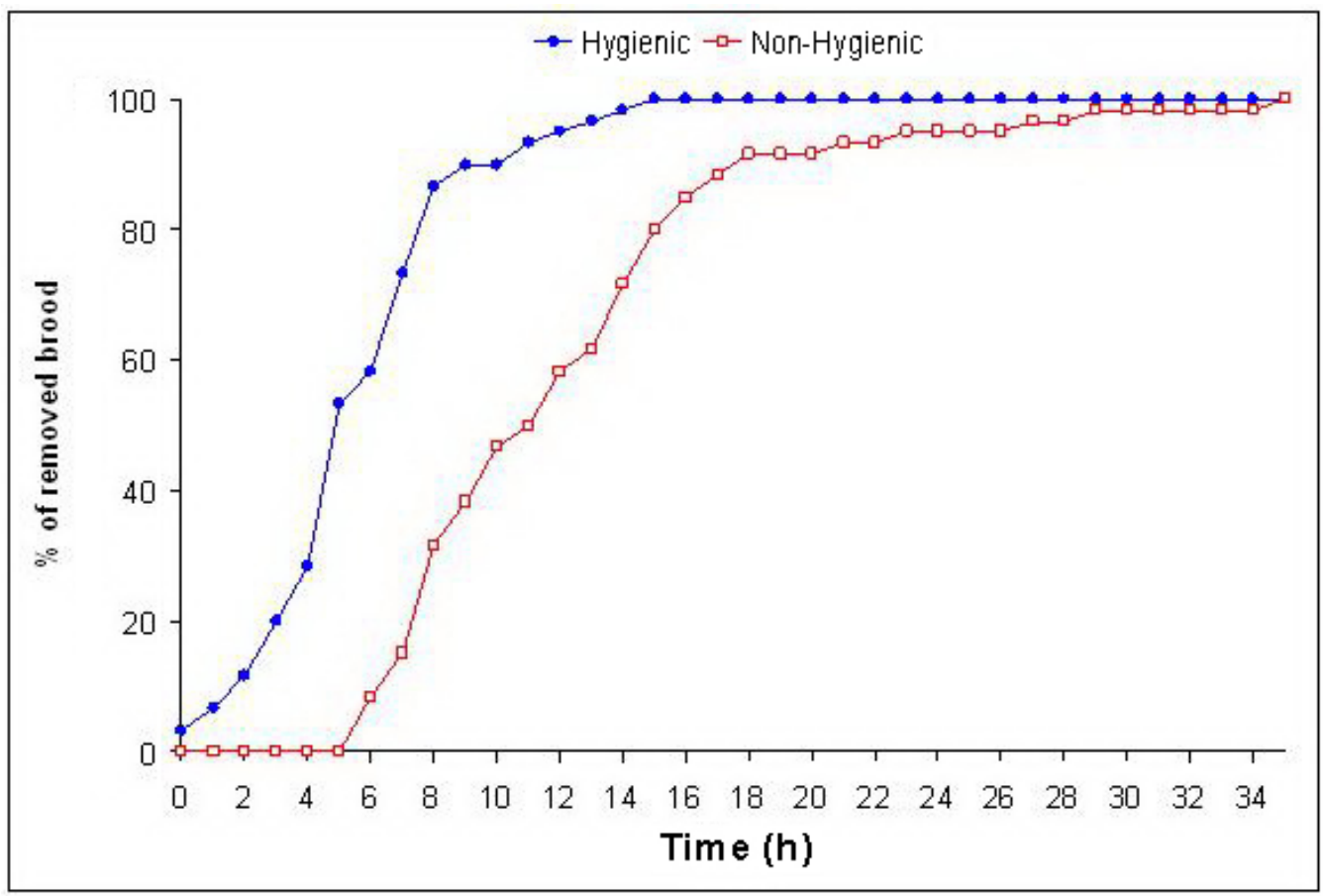

Figure 4. Time of removal of the dead brood by hygienic and non-hygienic Africanized bees after the perforation of the brood.

\section{DISCUSSION}

Though hygienic behavior has been very well studied, most of research has focused on the final efficiency of the colonies, and the intermediate steps of this behavior have been little studied. We analyzed hour by hour the stages of uncapping and removal of the dead brood to determine if there are differences in these intermediate stages in $\mathrm{H}$ and $\mathrm{NH}$ honey bees. As the hygienic colonies were more efficient in detecting the dead brood inside the capped cell, there may be some physiological differences between the two groups. In fact, differences in the olfactory discrimination ability between $\mathrm{H}$ and $\mathrm{NH}$ honey bees have been found using proboscis extension reflex studies (Masterman et al., 2001). Gramacho and Spivak (2003) found that the number of olfactory structures in the antennae is slightly higher in hygienic bees, though the differences were not significant.

Hygienic bees are also more efficient in uncapping and removing dead brood, indicating that there are also behavioral differences between the two groups. Pereira RA, Morais MM, Francoy TM and Gonçalves LS (unpublished results) showed that non-hygienic bees spend more time idle than do hygienic bees. This may explain the greater efficiency of hygienic bees in uncapping and removing dead or damaged brood.

Gramacho (1999), studying the time of uncapping and removal of dead brood in $A$. $m$. carnica, found that the bees started to work on the perforated cell after $2 \mathrm{~h}$. Palácio et al. (2005) observed that $1 \mathrm{~h}$ after pin killing of the brood, bees already detect the dead brood. We found that some dead brood was already uncapped and removed after 5 to $10 \mathrm{~min}$, indicating 
the great sensibility of Africanized hygienic bees. Accentuated hygienic behavior apparently is one of the most important factors contributing to the great disease resistance of these bees (Shimanuki et al., 1991).

The intermediate stages of hygienic behavior were first studied by Gramacho (1999), at intervals of $2 \mathrm{~h}$, using Langstroth hives and by Palácio et al. (2005), using observation hives. Gramacho (1999) evaluated the uncapping and removal stages until $10 \mathrm{~h}$ after perforation and Palácio et al. (2005) observed until $6 \mathrm{~h}$ after perforation. Both studies also checked removal 24 $\mathrm{h}$ after perforation. Gramacho (1999) found removal rates of between 1 and $31.6 \% 6 \mathrm{~h}$ after pin killing and Palácio et al. (2005) found 64\% removal in $\mathrm{H}$ colonies and $26 \%$ in NH colonies. We found that $\mathrm{H}$ colonies removed $58 \%$ and $\mathrm{NH}$ colonies removed only $8 \%$ of the dead brood. Though both experiments (Gramacho, 1999; Palácio et al., 2005) were done with honey bees of European origin, a fair comparison is only possible with the data from Gramacho (1999), since she reported real percentages while Palácio et al. (2005) reported relative percentages. We conclude that the efficiency of hygienic behavior is higher in Africanized bees, not only at the final stage, but also during the intermediate phases.

\section{ACKNOWLEDGMENTS}

We dedicate this study to Prof. Dr. Warwick Estevam Kerr. We also acknowledge the essential help of the apiary technician Adelino Penatti. Research supported by CAPES, CNPq and FAPESP.

\section{REFERENCES}

Adams J, Rothman ED, Kerr WE and Paulino ZL (1977). Estimation of the number of sex alleles and queen matings from diploid male frequencies in a population of Apis mellifera. Genetics 86: 583-596.

Gramacho KP (1999). Fatores que Interferem no Comportamento Higiênico das Abelhas Apis mellifera. Faculdade de Filosofia, Ciências e Letras de Ribeirão Preto, Universidade de São Paulo, Ribeirão Preto.

Gramacho KP and Gonçalves LS (1994). Estudo Comparativo dos Métodos de Congelamento e Perfuração de Crias para Avaliação do Comportamento Higiênico em Abelhas Africanizadas. In: Congresso Latinoiberoamericano de Apicultura, 4, Cordoba, Argentina. Anais, 45.

Gramacho KP and Spivak M (2003). Differences in olfactory sensitivity and behavioral responses among honey bees bred for hygienic behavior. Behav. Ecol. Sociobiol. 54: 472-479.

Lapidge KL, Oldroyd BP and Spivak M (2002). Seven suggestive quantitative trait loci influence hygienic behavior of honey bees. Naturwissenschaften 89: 565-568.

Masterman R, Ross R, Mesce K and Spivak M (2001). Olfactory and behavioral response thresholds to odors of diseased blood differ between hygienic and non-hygienic honey bees (Apis mellifera L.). J. Comp. Physiol. 187: 441-452.

Moritz RFA (1988). A reevaluation of the two-locus model for hygienic behavior in honeybees (Apis mellifera L.). J. Hered. 79: 257-262.

Page RE and Robinson GE (1991). The genetics of division of labour in honey bee colonies. Adv. Insect Physiol. 23: 117-169.

Palácio MA, Flores JM, Figini E, Ruffinengo S, et al. (2005). Evaluation of the time of uncapping and removing dead brood from cells by hygienic and non-hygienic honey bees. Genet. Mol. Res. 4: 105-114.

Rothenbuhler W (1964a). Behavior genetics of nest cleaning in honey bees. I. Response of four inbred lines to diseasekilled brood. Anim. Behav. 12: 578-583.

Rothenbuhler WC (1964b). Behavior genetics of nest cleaning in honey bees. IV. Responses of F1 and backcross generations to disease-killed blood. Am. Zool. 4: 111-123.

Shimanuki H, Knox D and De Jong D (1991). Bee Diseases, Parasites and Pests. In: The African Honey Bee (Spivak M, Fletcher DJC and Breed MD, eds.). Westview Press, Boulder, 283-296.

Spivak M, Masterman R, Ross R and Mesce KA (2003). Hygienic behavior in the honey bee (Apis mellifera L.) and the modulatory role of octopamine. J. Neurobiol. 55: 341-354. 